\title{
Anti-senescence Activity of Chemicals Applied to Kentucky Bluegrass
}

\author{
J.M. Goatley, Jr. ${ }^{1}$ and R.E. Schmidt ${ }^{2}$ \\ Department of Crop and Soil Environmental Sciences, Virginia Polytechnic Institute and State \\ University, Blacksburg, VA 24061
}

\begin{abstract}
Additional index words. Poa pratensis, leaf senescence, carbon dioxide exchange, iron, triazoles
Abstract. This study was conducted to determine the potential anti-senescence activity of certain chemicals by monitoring changes in gross. $\mathrm{CO}_{2}$ exchange with senescence of excised leaves of Kentucky bluegrass (Poa pratensis L.). One day following foliar applications of benzyladenine (BA), triadimefon, and propiconazole, with and without chelated Fe (8\% Fe phosphate citrate), Kentucky bluegrass leaves were excised, floated on distilled water in petri dishes, and placed in a darkened growth chamber. Gross $\mathrm{CO}_{2}$ exchange rates (CER) were recorded 1 , 4, 7 , and 10 days after excision (DAE). Foliar applications of $\mathrm{Fe}, \mathrm{BA}$, triadimefon, or propiconazole applied alone induced an anti-senescence response. Combinations of Fe with the chemicals delayed excision-induced leaf senescence, but no significant increase in anti-senescence activity was obtained from the Fe and chemical combinations as compared to the materials applied alone. Chemical names used: N-(phenylmethyl)-1H-purin-6-amine (benzyladenine, BA); 1-(4Chlorophenoxy)-3,3-dimethyl-1(1H-1,2,4-triazol-1yl)-2-butanone (triadimefon);1-[[2-(2,4-dichlorophenyl)-4-propyl1,3-dioxolan-2-yl]methyl]-1H-1,2,4-triazole (propiconazole).
\end{abstract}

Foliar treatments with BA, a synthetic cytokinin, have delayed or prevented leaf senescence in many plants (Thimann, 1980; Kane and Smiley, 1983; Tao et al., 1983). Triadimefon and propiconazole, systemic triazole fungicides frequently used for plant disease control, have delayed senescence of small grain crops in the field (Kettlewell et al., 1982; Baker et al., 1984). Kane and Smiley (1983) reported that triadimefon increased chlorophyll retention of Kentucky bluegrass leaves. Foliar applications of chelated $\mathrm{Fe}$ have also been reported to delay senescence of french bean (Phaseolus spp.) (Garg and Hemantaranjan, 1988). The greening effect of foliar applications of Fe on Kentucky bluegrass has been documented (Yust et al., 1984) and has been attributed to the requirement of $\mathrm{Fe}$ as a precursor in chlorophyll biosynthesis (Miller et al., 1982).

The objective of this research was to determine the potential anti-senescence activity of triadimefon, propiconazole, or BA applied alone and with chelated Fe on excised Kentucky bluegrass leaves.

\section{Materials and Methods}

Experiments were performed in October and repeated in December 1987. Kentucky bluegrass 'Georgetown' plugs $(5 \mathrm{~cm}$ in diameter and $7.5 \mathrm{~cm}$ deep) were taken from the field 4 weeks before the initiation of the October study. The plugs were planted in $7.6-\mathrm{cm}\left(215 \mathrm{~cm}^{3}\right)$ diameter styrofoam cups filled with a Groseclose silt loam soil (a clayey, kaolinitic mesic Typic Hapludult) with a $\mathrm{pH}$ of 6.2 . Holes were punched in the bottom of each cup and the plugs were subirrigated by placing the cups on a plastic-lined greenhouse bench containing $2.5 \mathrm{~cm}$ of water.

Triadimefon, propiconazole, and BA were applied to the Kentucky bluegrass at levels of 150,42 , or $6 \mathrm{mg}$ a.i./ $\mathrm{m}^{2}$ growing area, respectively. Chelated Fe phosphate citrate (RGB Laboratories, Kansas City, Mo.) was applied alone or in combination with the three organic materials at $112 \mathrm{mg} \mathrm{Fe} / \mathrm{m}^{2}$ area. All

\footnotetext{
Received for publication 27 Feb. 1989. Funding provided by Virginia Agriculture Experiment Station. The cost of publishing this paper was defrayed in part by the payment of page charges. Under postal regulations, this paper therefore must be hereby marked advertisement solely to indicate this fact.

${ }^{1}$ Assistant Professor. Present address: Dept. of Agronomy, Mississippi State Univ., Mississippi State, MS 39762.

${ }^{2}$ Professor, Dept. of Crop and Soil Environmental Sciences.
}

materials were applied with a compressed-air boom sprayer that delivered 123 liter $\cdot \mathrm{ha}^{-1}$ at a pressure of $276 \mathrm{kPa}$. Plugs were sprayed twice to ensure sufficient leaf coverage.

The youngest fully expanded leaves were excised from individual plants 1 day after spraying. Leaf tips were removed and $3 \mathrm{~cm}^{2}$ of leaf tissue were harvested. Excised leaf segments were floated on distilled water in uncovered petri dishes and placed in a dark growth chamber maintained at 22C to accelerate senescence (Thimann and Satler, 1979). The experiment was designed as a completely randomized $4 \times 2$ factorial ( 4 chemical treatments $\times 2$ Fe levels) observing the effects of BA or the triazoles applied with and without Fe across the four measurement dates. Each treatment was replicated five times.

Measurements of gross CER of detached leaves were made on the same leaf 1, 4, 7, and 10 DAE. Leaves were removed from the petri dishes in the darkened growth chamber just before measurement, blotted dry on tissue paper, and immediately placed in a Decagon LD-2 (Decagon, Pullman, Wash. ) leaf disk electrode unit with an effective chamber volume of $5 \mathrm{~cm}^{3}$ that enclosed the $3 \mathrm{~cm}^{2}$ of leaf tissue. The opened air flow rate into the sample chamber and reference line was 0.05 liter $\cdot \mathrm{min}^{-1}$. Differential $\mathrm{CO}_{2}$ concentrations were monitored by passing standard and sample air lines through an infrared gas analyzer (model AR-600, Anarad, Santa Barbara, Calif.). Dark respiration $\mathrm{CO}_{2}$ exchange was allowed to reach a steady-state level and this value was recorded.

Measurement of $\mathrm{CO}_{2}$ exchange in the light was initiated by turning on a light source mounted $30.5 \mathrm{~cm}$ above the LD-2 chamber that was focused through a $150-\mathrm{mm}$ lens and delivered $750 \mu \mathrm{mol} \cdot \mathrm{s}^{-1} \cdot \mathrm{m}^{-2}$. The temperature of the leaf segments was maintained at $20 \mathrm{C}$ by pumping cooled water through the waterjacketed chamber. Steady-state CER values attained in light and darkness were recorded and gross CER was calculated by subtracting $\mathrm{CO}_{2}$ exchange in the dark from $\mathrm{CO}_{2}$ exchange in the light (Edmisten and Wolf, 1988).

Repeated time analyses using Wilke's criterion for the hypotheses of time effects and time $\times$ treatment interactions were performed, since repeated measurements were made on the same leaf material (Morrison, 1976). Data for gross CER measure-

Abbreviations: $\mathrm{CER}, \mathrm{CO}_{2}$ exchange rates; DAE, days after leaf excision, 
ments were analyzed by contrasts and Dunnett's procedure for each date when time effects were significant.

\section{Results and Discussion}

Multivariate analyses using Wilke's criterion showed time to be highly significant and the time $\times$ treatment interaction to be nonsignificant for CER data. Contrasts and Dunnett's procedure for treatment comparisons with a control were used as statistical analyses for each date of measurement for the CER data. Single degree of freedom contrasts indicated very few differences in any comparison of organic chemical treatments when applied alone or with chelated Fe. Therefore, these statistical analyses are not presented.

The gross CER decline for both experiments with time was anticipated as excision-induced senescence progressed (Table 1). The trend for decline in gross CER across time for the October experiment was linear, while gross CER values leveled off at 7 DAE in the December experiment (Table 1). Comparisons of CER values between chemical treatments and the untreated control indicated that the majority of differences were detected 10 DAE in the October experiment (Table 2). Although not significantly different from the control, all treated leaves, except for the triadimefon plus Fe treatment, tended to have larger CER values at $7 \mathrm{DAE}$ in the October experiment (Table 2). BA, BA plus $\mathrm{Fe}$, propiconazole, and $\mathrm{Fe}$ alone had significantly larger CER values 10 DAE in the October experiment.

Only propiconazole alone and BA plus Fe at 4 and 7 DAE, respectively, and $\mathrm{BA}$ plus $\mathrm{Fe}$ or propiconazole plus Fe at 10 DAE significantly increased gross CER over nontreated leaves in December (Table 2). Still, CER values for all treated leaves tended to be larger than the control leaves 10 DAE.

Foliar applications of chelated Fe applied alone resulted in CER values similar to those obtained with the combinations of BA or triazoles with Fe (Table 2). The CER values for the combination treatment of triadimefon plus $\mathrm{Fe}$ were unexplainably low 7 and 10 DAE in the October experiment. Contrasts comparing the grouping of organic materials plus $\mathrm{Fe}$ vs. Fe alone were not significantly different (statistical data not presented). This result indicated no additional or synergistic response in retarding senescence by combining chelated Fe with BA, triadimefon, or propiconazole.

The synthetic cytokinin BA and the combination of BA and chelated Fe tended to maintain the highest CER values across the 10-day measurement period in both experiments (Table 2). Previous reports have documented the anti-senescence activity of BA (Tao et al., 1983). Garg and Hemantaranjan (1988) indicated that chelated $\mathrm{Fe}$ applications retarded leaf senescence, stimulated chlorophyll production, and increased photosynthetic rates in beans (Phaseolus spp.). Responses to treatments of propiconazole or triadimefon alone were not significantly different

Table 1. Mean CER of Kentucky bluegrass leaves treated with combinations of $\mathrm{Fe}, \mathrm{BA}$, and triazoles 1 day before excision.

\begin{tabular}{lcccr}
\hline \hline & \multicolumn{4}{c}{$\begin{array}{c}\text { Gross CER } \\
\left(\mu \mathrm{mol} \cdot \mathrm{s}^{-1} \cdot \mathrm{m}^{-2}\right)\end{array}$} \\
\cline { 2 - 5 } Experiment & \multicolumn{4}{c}{$\mathrm{DAE}$} \\
\hline October & 3.8 & 4 & 7 & 10 \\
December & 3.8 & 3.5 & 1.9 & 0.8 \\
\hline
\end{tabular}

'Values are means of five replications; none of the interactions were significant.
Table 2. CER of Kentucky bluegrass leaves 1, 4, 7, and 10 DAE following foliar applications of $\mathrm{BA}$ and triazoles alone or with $\mathrm{Fe}$.

\begin{tabular}{|c|c|c|c|c|c|c|}
\hline \multirow[b]{3}{*}{ Chemical } & & & \multicolumn{4}{|c|}{$\begin{array}{c}\text { Gross CER } \\
\left(\mu \mathrm{mol} \cdot \mathrm{s}^{-1} \cdot \mathrm{m}^{-2}\right)\end{array}$} \\
\hline & \multicolumn{2}{|c|}{ Concentration $^{z}$} & \multicolumn{4}{|c|}{ DAE } \\
\hline & Chemical & $\mathrm{Fe}$ & 1 & 4 & 7 & 10 \\
\hline \multicolumn{7}{|c|}{ October } \\
\hline \multirow[t]{2}{*}{ None } & 0 & 0 & 2.34 & 2.75 & 1.51 & 0.30 \\
\hline & 0 & 112 & 3.26 & 3.88 & 2.34 & $1.01^{*}$ \\
\hline \multirow[t]{2}{*}{$\mathrm{BA}$} & 6 & 0 & 4.31 & 3.99 & 2.30 & $1.10^{*}$ \\
\hline & 6 & 112 & 3.90 & 3.01 & 2.50 & $1.15^{*}$ \\
\hline \multirow[t]{2}{*}{ Propiconazole } & 42 & 0 & 4.29 & $4.29^{*}$ & 2.16 & $0.90^{*}$ \\
\hline & 42 & 112 & $5.83^{*}$ & 3.81 & 2.27 & 0.71 \\
\hline \multirow[t]{2}{*}{ Triadimefon } & 150 & 0 & 3.30 & 3.79 & 1.97 & 0.71 \\
\hline & 150 & 112 & 2.89 & 2.71 & 0.57 & 0.16 \\
\hline \multirow[t]{2}{*}{ LSD } & --- & -- & 2.25 & 1.39 & 1.03 & 0.57 \\
\hline & \multicolumn{6}{|c|}{ December } \\
\hline \multirow[t]{2}{*}{ None } & 0 & 0 & 3.60 & 1.33 & 0.83 & 0.64 \\
\hline & 0 & 112 & 4.27 & 2.11 & 1.70 & 1.33 \\
\hline \multirow[t]{2}{*}{$\mathrm{BA}$} & 6 & 0 & 3.46 & 2.80 & 1.33 & 1.77 \\
\hline & 6 & 112 & 4.40 & 2.13 & $2.59^{*}$ & $1.97^{*}$ \\
\hline \multirow{2}{*}{ Propiconazole } & 42 & 0 & 3.63 & $2.96^{*}$ & 1.54 & 1.38 \\
\hline & 42 & 112 & 3.97 & 2.18 & 1.75 & $2.23^{*}$ \\
\hline \multirow{2}{*}{ Triadimefon } & 150 & 0 & 2.98 & 1.72 & 0.96 & 0.99 \\
\hline & 150 & 112 & 4.27 & 2.39 & 1.68 & 1.49 \\
\hline LSD & -- & -- & 2.17 & 1.58 & 0.92 & 1.29 \\
\hline
\end{tabular}

${ }^{2}$ Levels expressed in milligrams of active ingredient applied per square meter of growing area.

${ }^{y}$ Values are means of five replications consisting of $3 \mathrm{~cm}^{2}$ of leaf tissue per replication.

"Values within the same column and same experiment are significantly different from the control at $P=0.05$, according to Dunnett's test.

from each other at any time in either experiment (Table 2). The triazole-treated leaves tended to have CER values similar to BAtreated leaves, suggesting cytokinin-like activity of the triazoles.

As endogenous plant growth substances, cytokinins have acted as anti-senescence agents (Thimann, 1980). The triazoles have exhibited cytokinin-like growth effects on certain plants, but Fletcher and Arnold (1986) reported that the growth activity of triadimefon was a stimulation of root growth that indirectly could have led to increased plant cytokinin levels. Since the leaves in these experiments were excised 1 day after treatment, it is unlikely the anti-senescence response could have come from a promotion of plant cytokinin synthesis.

Prior studies with BA, the triazoles, and Fe indicated each of these chemicals generally stimulated both chlorophyll production and photosynthetic rates (Kane and Smiley, 1983; Kettlewell et al., 1982; Garg and Hemantaranjan, 1988). In our experiment, the treatments apparently maintained chlorophyll activity or at least retarded chlorophyll degradation. Frequent observations of leaf color as senescence progressed suggested that the rate of chlorophyll degradation in the treated leaves was reduced, since these leaves remained greener than the untreated leaves.

Foliar applications of triadimefon, propiconazole, and $\mathrm{Fe}$ are a part of many turfgrass maintenance programs. In addition to their respective uses as fungicides or fertilizers, the anti-senescence activity could theoretically promote an increase in photosynthetically active leaf area for the turf plant and further enhance plant growth and development. Further research to examine anti-senescence activity and growth regulator activities on intact plants is necessary to determine if these responses can be obtained in the field. 


\section{Literature Cited}

Baker, J., P.S. Kettlewell, W. Davies, and T.J. Hocking. 1984. Evaluation of late season fungicides for effects on leaf senescence in winter wheat, Ann. Applied Biol. (Suppl.) 104:42-43.

Edmisten, K.L. and D.D. Wolf. 1988. Fall harvest management of alfalfa. II The implications of photosynthesis, respiration, and taproot nonstructural carbohydrate accumulation on fall harvest management. Agron. J. 80:693-698.

Fletcher, R.A. and V. Arnold. 1986. Stimulation of cytokinins and chlorophyll synthesis in cucumber cotyledons by triadimefon. Physiol. Plant. 66: 197-201.

Garg, O.K., and A. Hemantaranjan. 1988. Iron sources in relation to leaf senescence in french bean (Phaseolus vulgaris L.). J. Plant Nutr. 9:1205-1215.

Kane, R.T. and R.W. Smiley. 1983. Plant growth-regulating effects of systemic fungicides applied to Kentucky bluegrass. Agron. J. 75:469-473.

Kettlewell, P.S., W.P. Davies, and T.J. Hocking. 1982. Disease de- velopment and senescence of the flag leaf of winter wheat in response to propiconazole. J. Agr. Sci. 99:661-663.

Miller, G.W., A. Denney, J. Pushnik, and M. Yo. 1982. The formation of delta-aminolevulinate, a precursor of chlorophyll, in barley and the role of iron. J. Plant Nutr. 5:289-300.

Morrison, D.F. 1976. Multivariate statistical methods. 2nd ed. McGraw-Hill, New York.

Tao, G.Q., D.S. Letham, L.M.S. Palni, and R.E. Summons. 1983. Cytokinin biochemistry in relation to leaf senescence. I. The metabolism of 6-benzylaminopurine and zeatin in oat leaf segments. J. Plant Growth Regulat. 1:89-102.

Thimann, K.V. 1980. The senescence of leaves, p. 85-115. In: K.V. Thimann (ed.). Senescence implants. CRC, Boca Raton, Fla.

Thimann, K.V. and S.O. Satler. 1979. Relation between senescence and stomatal opening: senescence in darkness. Proc. Natl. Acad. Sci. (USA) 76:2295-2298.

Yust, A.K., D.J. Wehner, and T.W. Fermanian. 1984. Foliar applications of $\mathrm{N}$ and Fe to Kentucky bluegrass. Agron. J. 76:934-938. 